\title{
Relamorelin to Treat Constipation: "Pusher" or Pushover?
}

\author{
Gabrio Bassotti ${ }^{1,2}$
}

Published online: 24 October 2015

(c) Springer Science+Business Media New York 2015

The propulsion of colonic contents throughout the large bowel is one of the main mechanisms involved in the act of defecation. The advancement of these contents is due to a complex interplay that involves both segmental and propagated motor activity, with the latter featuring a paramount role in shifting contents within the lumen. Although the pathophysiologic basis of chronic constipation is still incompletely understood [1], feeble or absent colonic propagated activity is often observed in these patients $[2$, 3]. Therefore, since drugs can increase the frequency and amplitude of colonic contractions, especially the manometric equivalents of mass movements, termed high-amplitude propagated contractions [4], such medications could prove useful tools in constipation treatment. To date, objective documentation in humans of such stimulation is available for only a few clinically available drugs, including bisacodyl [5], macrogol [6], chenodeoxycholic acid [7], and prucalopride [8].

Caution should, however, be the rule when interpretating such data, since some of these studies have been conducted only in healthy volunteers [6-8], and at least for one of them the findings have not been reproduced in either controls or patients [9]; therefore, further data, possibly obtained in patients with chronic constipation, would be indeed welcome.

Gabrio Bassotti

gabassot@tin.it

1 Gastroenterology and Hepatology Section, Department of Medicine, University of Perugia Medical School, Perugia, Italy

2 Clinica di Gastroenterologia ed Epatologia, Ospedale Santa Maria della Misericordia, Piazzale Menghini, 1, 06156 San Sisto, Perugia, Italy
In recent years, there had been interest in ghrelin, an orexigenic hormone secreted by the stomach that stimulates gut motility by signaling via the vagus nerve in the upper gastrointestinal tract and the pelvic nerves in the colon [10].

In this issue of Digestive Diseases and Sciences, Acosta and colleagues report their experience with the pentapeptide ghrelin agonist, relamorelin, a drug that accelerates colonic transit and increases the number of spontaneous bowel movements, on the motility and compliance of the descending colon in chronically constipated patients [11]. Although the study was conducted in a brief time framethe overall investigation period lasted $4 \mathrm{~h}$ and the drug effect was evaluated for only $1 \mathrm{~h}$ after meal ingestion-it was conducted by a well-designed protocol using a manometry-barostat assembly that enabled the concomitant recording of left colonic tone. Subcutaneous injection of relamorelin, $100 \mu \mathrm{g}$, stimulated high- and low-amplitude propagated activity in the left colon of these patients while not influencing the basal or postprandial phasic motor activity, nor wall compliance or visceral sensation.

The main limitation of this study was that since it was carried out over a relatively short time period, the effects of relamorelin in the time course following its administration were not available; however, recent publications from the same group reported that this drug maintains its clinical efficacy for hours in patients complaining of chronic constipation [12], suggesting that the propulsive effects of relamorelin might last longer than the hour reported in the present study.

All in all, the available literature and those provided in the study suggest that since relamorelin might be considered as a relatively pure "pusher," at least in the colon, this drug may be effective in the treatment of constipation, even though its propulsive effects seem to be relatively feeble 
when compared with those characteristic of other drugs [58]. Nevertheless, its ability to stimulate proximal gut motility [11] combined with its subcutaneous route of administration might benefit not only conventional constipated subjects, but also other subtypes of constipation such as in post-operative and neutrally compromised patients, and in patients refractory to all other medications [13]. Indeed, having available new drugs with different mechanisms of action would likely offer the possibility of affecting multiple pathways, increasing the probability of therapeutic success, thereby avoiding more invasive options such as surgery.

Indeed, it is frustrating that notwithstanding numerous published reports, there are still too few drugs specifically intended to treat constipation; the recent demonstration of abnormalities within the enteric nervous system in at least the more severely affected patients [14] might in the future address the research in a more targeted manner, focusing on the correction or the augmentation of failing mechanisms such as propulsion or response to eating by acting on specific cell populations (particularly the enteric glia) that appear to be of importance to the pathophysiology of this condition [15].

In the meantime, as we look forward to future developments, the availability of new drugs with novel mechanisms of action should be a boon to patients with refractory severe constipation. By discovering new therapeutic targets, it is likely that new drugs will follow which greatly alleviate the suffering experienced by this large but unheralded population.

\section{Compliance with ethical standards}

Conflict of interest None.

\section{References}

1. Bassotti G, de Roberto G, Castellani D, Sediari L, Morelli A. Normal aspects of colorectal motility and abnormalities in slow transit constipation. World J Gastroenterol. 2005;11:2691-2696.
2. Bassotti G, Gaburri M, Imbimbo BP, Rossi L, et al. Colonic mass movements in idiopathic chronic constipation. Gut. 1988;29: 1173-1179.

3. Bassotti G, Chistolini F, Nzepa FS, Morelli A. Colonic propulsive impairment in intractable slow-transit constipation. Arch Surg. 2003;138:1302-1304.

4. Narducci F, Bassotti G, Gaburri M, Morelli A. Twenty four hour manometric recording of colonic motor activity in healthy man. Gut. 1987;28:17-25.

5. Bassotti G, Chiarioni G, Germani U, Battaglia E, Vantini I, Morelli A. Endoluminal instillation of bisacodyl in patients with severe (slow transit type) constipation is useful to test residual colonic propulsive activity. Digestion. 1999;60:69-73.

6. Lémann M, Flourié B, Picon L, Coffin B, Jian R, Rambaud JC. Motor activity recorded in the unprepared colon of healthy humans. Gut. 1995;37:649-653.

7. Bampton PA, Dinning PG, Kennedy ML, Lubowski DZ, Cook IJ. The proximal colonic motor response to rectal mechanical and chemical stimulation. Am J Physiol Gastrointest Liver Physiol. 2002;282:G443-G449.

8. De Schryver AM, Andriesse GI, Samsom M, Smout AJ, Gooszen HG, Akkermans LM. The effects of the specific 5HT(4) receptor agonist, prucalopride, on colonic motility in healthy volunteers. Aliment Pharmacol Ther. 2002;16:603-612.

9. Herve S, Leroi AM, Mathiex-Fortunet H, Garnier P, et al. Effects of polyethylene glycol 4000 on 24-h manometric recordings of left colonic motor activity. Eur J Gastroenterol Hepatol. 2001;13:647-654.

10. Avau B, Carbone F, Tack J, Depoortere I. Ghrelin signaling in the gut, its physiological properties, and therapeutic potential. $\mathrm{Neu}$ rogastroenterol Motil. 2013;25:720-732.

11. Acosta A, Camilleri M, Busciglio I, Boldingh A, Nelson AD, Burton D. Short-term effects of relamorelin on descending colon motility in chronic constipation: a randomized, controlled trial. Dig Dis Sci. (Epub ahead of print). doi:10.1007/s10620-0153876-5.

12. Acosta A, Camilleri M, Kolar G, et al. Phase II, placebo-controlled efficacy, safety, and pharmacodynamics trial of relamorelin in chronic constipation. Clin Gastroenterol Hepatol. 2015 (in press).

13. Bassotti G, Blandizzi C. Understanding and treating refractory constipation. World J Gastrointest Pharmacol Ther. 2014;5: 77-85.

14. Bassotti G, Villanacci V, Maurer CA, Fisogni S, et al. The role of glial cells and apoptosis of enteric neurones in the neuropathology of intractable slow transit constipation. Gut. 2006;55:41-46.

15. Bassotti G, Villanacci V. Can, "functional" constipation be considered as a form of enteric neuro-gliopathy? Glia. 2011;59: $345-350$. 